\title{
Risk Assessment and Countermeasures of Heavy Metals in Drinking Water Environment of Guizhou Province
}

\author{
Bing Yang ${ }^{1}$, Hong Yang ${ }^{2}$, Chengmei Zhang ${ }^{1}$ and Yajie Wang ${ }^{1, *}$ \\ ${ }^{1}$ Guizhou Academy of Testing and Analysis, Guiyang, China \\ ${ }^{2}$ Guizhou Academy of Sciences Big Data Co.LTD, Guiyang, China
}

\begin{abstract}
The quality of drinking water is closely related to the health condition of the population. In order to effectively assess the heavy metal environment of drinking water in Guizhou Province, this paper first analyzed the distribution characteristics of heavy metals in drinking water, and then used the environmental health risk assessment model recommended by the United States Environmental Protection Agency (US EPA) to investigate and analyze the toxic and hazardous substances in drinking water in Guizhou Province in 2019 to assess the health risks of heavy metals in drinking water. The survey results showed that the cancer-causing health risks of drinking water in Guizhou Province exceeded the EPA evaluation standards, while the non-cancer-causing health risks were much lower than the evaluation standards. Finally, for the heavy metal environment of drinking water in Guizhou province, this paper proposes corresponding response strategies from two perspectives of water quality monitoring and government supervision.
\end{abstract}

\section{Introduction}

Water quality is closely related to human health and is the basic material basis for human survival. World Health Organization research shows that most human diseases are caused by unsafe water and poor sanitary conditions caused by water shortage. Long-term consumption of unclean water is most detrimental to the healthy growth of children and will directly affect the quality of the population. Ensuring the safety of drinking water is an important condition to ensure human health and human development. With the progress of society, especially now is in is a critical period of accelerated industrialization and urbanization, China is facing the pressure and risk of water shortage and deterioration of water environment. Real-time understanding of water quality conditions and maintenance of water safety has become China's current letter to be solved [1-2].

Currently, a lot of drinking water pollution is caused by heavy metals. Heavy metals are mainly metals with density above $4.5 \mathrm{~g} / \mathrm{cm}^{3}$, which have certain toxicity, including $\mathrm{Fe}, \mathrm{Mn}, \mathrm{Cu}, \mathrm{Cd}, \mathrm{Hg}$, Ni and other 45 elements, among which $\mathrm{Cu}, \mathrm{Zn}, \mathrm{Fe}$ and other metal elements are essential trace elements, but most of the elements are not necessary for life activities. AS is a non-metal, but its toxicity and some properties are similar to those of heavy metals, so it is also classified as a heavy metal. The heavy metals present in nature are lightly hazardous, but the solid wastes, waste water, and exhaust gases generated by the industrialized production in modern society enter the water bodies, upper soil, and plants, causing serious pollution of heavy metals in the environment, and their pollution has a wide range, accumulation, concealment, long duration, and difficulty in degradation,. They even combine with organic matter through chemical and biological effects to form more toxic organic metals. In recent years, groundwater, farmland and crops are increasingly contaminated by heavy metals globally, which directly or indirectly lead to the increase of heavy metal content in drinking water, thus posing a threat to human health. Therefore, it is necessary to monitor and assess the heavy metals in drinking water [3-4].

Health risk assessment is a new technical method established and developed in the last decade or so. It evaluates the risk of health effects on individuals exposed to a hazardous factor by estimating the probability of its adverse effects on the human body [5]. In 1976, the Environmental Protection Agency (EPA) published guidelines for evaluating the risk of suspected carcinogens. In 1983, the National Academy of Sciences prepared a study on health risk evaluation methods, and the risk evaluation procedures and the technical terms proposed in this report were generally accepted, thus standardizing the health risk evaluation methods. This paper uses the risk assessment model recommended by the EPA, combined with local drinking water exposure parameters, to quantitatively describe the possibility of heavy metal substance contamination in drinking water in Guizhou Province causing harm to residents' health, and to target the relevant response strategies.

\section{Study subjects and methods}

\subsection{Study subjects}

\footnotetext{
* Corresponding author: Yajia Wang, wangyajie@gzbdi.com
} 
From January 2019 to December 2019, a total of 660 water samples were collected from 120 sampling sites in Guiyang, Zunyi, Bijie and Anshun of Guizhou Province.

\subsection{Testing methods}

In this study, the samples were collected, preserved and tested in accordance with the relevant provisions of the Standard Test Methods for Drinking Water (GB /T5750 2006).

\subsection{Health risk assessment model}

The EPA proposed a total of four steps for health risk assessment, namely hazard identification, dose-response relationship, exposure assessment, and risk characterization. The contaminants in 660 water samples were evaluated. Among them, chemicals belonging to Groups 1 and 2A were classified as chemical carcinogens, mainly $\mathrm{Cr}^{6+}$, $\mathrm{As}$ and $\mathrm{Cd}$, and noncarcinogens including $\mathrm{Pb}, \mathrm{Hg}, \mathrm{Cu}, \mathrm{Zn}, \mathrm{Mn}, \mathrm{Al}$ and $\mathrm{Fe}$. According to the databases such as International Agency for Research on Cancer (IARC) and the Integrated Risk Information System (IRIS) of the U.S. Environmental Protection Agency, the reference doses (RfD) and carcinogenic intensity factors $\left(\mathrm{SF}_{0}\right)$ of the 10 heavy metals are shown in Table 1.

Table 1. Model Parameters

\begin{tabular}{|c|c|c|}
\hline Heavy metals & $\begin{array}{c}\mathrm{RfD} \\
{[\mathrm{mg} /(\mathrm{kg} \cdot \mathrm{d})]}\end{array}$ & $\begin{array}{c}\mathrm{SF}_{0} \\
{[(\mathrm{~kg} \cdot \mathrm{d}) / \mathrm{mg}]}\end{array}$ \\
\hline $\mathrm{As}$ & 0.0002 & 1.4 \\
\hline $\mathrm{Cd}$ & 0.0040 & 5.9 \\
\hline $\mathrm{Cr}^{6+}$ & 0.0028 & 40.2 \\
\hline $\mathrm{Pb}$ & 0.0012 & - \\
\hline $\mathrm{Hg}$ & 0.0001 & - \\
\hline $\mathrm{Al}$ & 1.0000 & - \\
\hline $\mathrm{Fe}$ & 0.8000 & - \\
\hline $\mathrm{Mn}$ & 0.1500 & - \\
\hline $\mathrm{Cu}$ & 0.0300 & - \\
\hline \multicolumn{2}{|c|}{$\begin{array}{l}\text { Zn } \\
\text { Note: " - means that the data is not available and does } \\
\text { not participate in the statistics }\end{array}$} \\
\hline
\end{tabular}

The daily water consumption of individuals in urban and rural areas of Guizhou Province was set at $2.5 \mathrm{~L}$ (0.6 $\mathrm{L}$ for indirect water consumption and $1.9 \mathrm{~L}$ for direct water consumption), the average weight of the population in Inner Mongolia was $63.0 \mathrm{~kg}$, and the life expectancy was 70 years.
Applying the EPA Health Risk Assessment Model, the health risk assessment model for chemical carcinogens is:

$$
\begin{gathered}
\mathrm{R}^{\mathrm{c}}=\sum_{\mathrm{i}=1}^{\mathrm{k}} \mathrm{R}_{\mathrm{mp}}^{\mathrm{c}} \\
\mathrm{R}_{\mathrm{mp}}^{\mathrm{c}}=\mathrm{AED}_{\mathrm{c}} \times \mathrm{SF}_{0} \\
\mathrm{AED}=\frac{\mathrm{C} \times \mathrm{AWC} \times \mathrm{EF} \times \mathrm{ET}}{\mathrm{AW} \times \mathrm{LT}}
\end{gathered}
$$

where $R^{c}$ is the risk of health hazards due to all carcinogenic metals. $R_{m p}^{c}$ is the risk of cancer from heavy metal $\mathrm{m}$ via the water consumed. $\mathrm{AED}_{\mathrm{c}}$ is the lifetime average daily dose per body weight of carcinogenic heavy metal $\mathrm{i}$ via ingestion. $\mathrm{SF}_{0}$ is the carcinogenic intensity factor $[(\mathrm{kg} \cdot \mathrm{d}) / \mathrm{mg}]$ for carcinogenic heavy metal $\mathrm{i}$ via ingestion. $\mathrm{C}$ is the concentration of chemical carcinogen $\mathrm{m}(\mathrm{mg} / \mathrm{L})$. AWC is the average daily water consumption of Inner Mongolia population, which is $2.5 \mathrm{~L}$. EF is the exposure frequency (d/a), which is $365 \mathrm{~d} / \mathrm{a}$; ET is the exposure duration (a), which is $60 \mathrm{a}$. BW is the average adult body weight (kg), which is $63.0 \mathrm{~kg}$. is the lifetime exposure time (d), which is $21900(60 \mathrm{a} \times 365 \mathrm{~d})$.

The health risk assessment model for noncarcinogens was :

$$
\begin{gathered}
\mathrm{R}^{\mathrm{n}}=\sum_{\mathrm{i}=1}^{\mathrm{k}} \mathrm{R}_{\mathrm{mp}}^{\mathrm{n}} \\
\mathrm{R}_{\mathrm{mp}}^{\mathrm{n}}=\mathrm{AED}_{\mathrm{n}} \times 10-6 / \mathrm{RFD}_{\mathrm{mp}} \\
\mathrm{AED}_{\mathrm{n}}=\frac{\mathrm{C} \times \mathrm{AWC} \times \mathrm{EF} \times \mathrm{ET}}{\mathrm{AW} \times \mathrm{AT}}
\end{gathered}
$$

Where $\mathrm{R}^{\mathrm{n}}$ is the risk of health hazards due to noncarcinogenic metals.. $\mathrm{R}_{\mathrm{mp}}^{\mathrm{n}}$ is the risk of health hazards caused by non-carcinogenic heavy metals $\mathrm{m}$ via drinking water. $\mathrm{AED}_{\mathrm{n}}$ is the lifetime average daily dose per body weight of non-carcinogenic heavy metals via drinking water $[\mathrm{mg} /(\mathrm{kg} \cdot \mathrm{d})] . \quad \mathrm{RfD}_{\mathrm{mp}}$ is the reference dose $[\mathrm{mg} /(\mathrm{kg} \cdot \mathrm{d})]$ of non-carcinogenic heavy metals via drinking water. AT is the average exposure time (d), which was taken as $10905 \mathrm{~d}(30 \mathrm{a} \times 365 \mathrm{~d})$.

The total health hazards of the water environment $\mathrm{R}^{\mathrm{T}}$ is:

$$
\mathrm{R}^{\mathrm{T}}=\mathrm{R}^{\mathrm{c}}+\mathrm{R}^{\mathrm{n}}
$$

\subsection{Health risk evaluation criteria}

The health risk of heavy metal contaminants in water is determined based on the EPA's evaluation criteria, which considers the acceptable level of risk for carcinogens to be in the order of magnitude of $10^{-6}$ to $10^{-4}$. If the carcinogenic risk of a pollutant is less than $10^{-6}$, it is considered to cause a small risk of cancer, if the carcinogenic risk is between $10^{-4}$ and $10^{-6}$, it is considered to have a carcinogenic risk, if the carcinogenic risk is greater than $10^{-4}$, it is considered to cause cancer. If the carcinogenic risk is greater than $10^{-4}$, it is considered to have a higher risk of causing cancer. For the risk of non-carcinogenic substances, if the hazard 
risk $<1$, it is considered that no damage is expected to the organism and the exposure is below the threshold of no harm; if the hazard risk $>1$, it means that the exposure dose exceeds the threshold and will cause damage to the organism.

\section{Analysis results}

\section{Heavy metal content in water samples from Guizhou Province}

Table 2. Heavy metal content in drinking water in Guizhou Province in 2019 ( $\mathrm{mg} / \mathrm{L}$ )

\begin{tabular}{|c|c|c|c|c|c|}
\hline Heavy metals & Median & $\mathrm{P} 25$ & $\mathrm{P} 75$ & Minimal value & Maximum value \\
\hline $\mathrm{As}$ & $4.00 \times 10^{-4}$ & $4.00 \times 10^{-4}$ & $1.00 \times 10^{-3}$ & $4.00 \times 10^{-4}$ & $4.52 \times 10^{-4}$ \\
\hline $\mathrm{Cd}$ & $2.60 \times 10^{-4}$ & $2.60 \times 10^{-4}$ & $4.00 \times 10^{-4}$ & $1.00 \times 10^{-4}$ & $1.00 \times 10^{-4}$ \\
\hline $\mathrm{Cr}^{6+}$ & $1.85 \times 10^{-3}$ & $1.85 \times 10^{-3}$ & $4.25 \times 10^{-3}$ & $3.00 \times 10^{-3}$ & $2.25 \times 10^{-3}$ \\
\hline $\mathrm{Pb}$ & $1.50 \times 10^{-3}$ & $1.50 \times 10^{-3}$ & $1.50 \times 10^{-3}$ & $6.00 \times 10^{-4}$ & $4.35 \times 10^{-4}$ \\
\hline $\mathrm{Hg}$ & $4.50 \times 10^{-5}$ & $4.50 \times 10^{-5}$ & $2.00 \times 10^{-4}$ & 0 & 0 \\
\hline $\mathrm{Al}$ & $4.80 \times 10^{-3}$ & $4.20 \times 10^{-3}$ & $2.00 \times 10^{-2}$ & $0.50 \times 10^{-3}$ & $1.23 \times 10^{-3}$ \\
\hline $\mathrm{Fe}$ & $1.15 \times 10^{-1}$ & $5.50 \times 10^{-2}$ & $1.50 \times 10^{-1}$ & $2.60 \times 10^{-4}$ & $3.20 \times 10^{-3}$ \\
\hline $\mathrm{Mn}$ & $5.00 \times 10^{-2}$ & $1.20 \times 10^{-2}$ & $6.00 \times 10^{-2}$ & $4.00 \times 10^{-4}$ & $4.15 \times 10^{-4}$ \\
\hline $\mathrm{Cu}$ & $5.50 \times 10^{-2}$ & $1.50 \times 10^{-2}$ & $0.50 \times 10^{-1}$ & $3.00 \times 10^{-3}$ & $4.38 \times 10^{-3}$ \\
\hline $\mathrm{Zn}$ & $2.00 \times 10^{-2}$ & $2.00 \times 10^{-2}$ & $2.00 \times 10^{-2}$ & $4.00 \times 10^{-4}$ & $6 . .25 \times 10^{-4}$ \\
\hline
\end{tabular}

\subsection{Health risks of different heavy metals}

The carcinogenic and non carcinogenic risks of different heavy metals are shown in Table 3 . The total non carcinogenic risk of heavy metals was $5.4533 \times 10^{-9}$, the total carcinogenic risk was $4.9904 \times 10^{-5}$, and the total health risk was $4.9903 \times 10^{-5}$. The order of carcinogenic risk of heavy metals was $\mathrm{Cr}^{6+}>\mathrm{Cd}>\mathrm{As}$. Among them, according to EPA evaluation criteria, hexavalent chromium is considered to have carcinogenic risk, while the non carcinogenic risk of heavy metals is $\mathrm{As}>\mathrm{Cu}>\mathrm{Cr}>\mathrm{Cd}>\mathrm{Fe}>\mathrm{Mn}>\mathrm{Pb}>\mathrm{Hg}>\mathrm{Zn}>\mathrm{Al}$. The non carcinogenic risk of all heavy metals is significantly less than 1 , and the total non carcinogenic risk is less than 1 , which is considered not exceeding EPA evaluation criteria.

Table 3. Carcinogenic and non-carcinogenic risks of different heavy metals in Guizhou Province, 2019

\begin{tabular}{|c|c|c|} 
Heavy metals & Carcinogenic risk & $\begin{array}{c}\text { Non-carcinogenic } \\
\text { risk }\end{array}$ \\
\hline
\end{tabular}

This paper determines the concentration of pollutants in drinking water in Guizhou Province in 2019. In 660 samples, $\mathrm{Cd}, \mathrm{Cr}^{6+}, \mathrm{Hg}, \mathrm{Al}, \mathrm{Cu}, \mathrm{Zn}$ are all qualified. 18 As samples failed, the qualified rate is $97.27 \%$. $3 \mathrm{Fe}$ samples failed, the qualified rate is $99.55 \%$. $1 \mathrm{Mn}$ samples failed manganese, the qualified rate is $99.85 \%$. The content of metals in drinking water of Guizhou Province in 2019 as shown in Table 2. 


\section{Conclusion}

In this paper, the health risk assessment of heavy metals in drinking water in Guizhou Province was conducted. According to the results of carcinogenic risk evaluation of $\mathrm{Cr}^{6+}, \mathrm{Cd}$ and $\mathrm{As}, \mathrm{Cr}^{6+}$ has the highest carcinogenic risk and exceeds the recommended limit value of EPA and has certain carcinogenic risk. Compared with arsenic and cadmium, the heavy metal chromium has a decisive role in the carcinogenic risk of water bodies, and attention should be paid to the risk management of chromium. The total non-carcinogenic risk of heavy metals is much less than the EPA recommended value. The overall non-carcinogenic health risk is small. The metals with the highest non-carcinogenic risk values are As, $\mathrm{Cu}$ and $\mathrm{Cr}^{6+}$.

This study only considered the health risk of heavy metal contaminant exposure through the drinking water route, and did not consider the exposure route. In addition, the samples taken are still small and do not cover all areas, so they may differ from the actual results, making the health risk evaluation results uncertain and need to be further improved in future work. The current survey generally shows that the drinking water quality in Guizhou Province basically meets the drinking standard, but still needs further improvement, so this paper puts forward the corresponding countermeasures.

\section{Countermeasures}

\subsection{Strengthen the online monitoring of water quality}

Due to the varying technical levels of drinking water plants, equipment models and quality are not the same, the traditional manual operation is difficult to meet the requirements of the majority of residents of drinking water quality. Therefore, it is recommended to improve the online monitoring system of drinking water quality in drinking water plants to form negative feedback on water quality. Improve the drinking water quality monitoring system, need to further strengthen the grassroots environmental monitoring station infrastructure capacity building, equipped with the appropriate monitoring instruments, training skilled operators, the completion of routine monitoring and basic emergency monitoring objectives. First of all, efforts should be made to accelerate the speed of standardized capacity building of grass-roots environmental monitoring stations, especially to strengthen the hardware facilities for monitoring drinking water sources, add, update some of the large, high degree of automation, high precision, practical monitoring and analysis instruments. Secondly, we should continuously strengthen the exchange and training efforts, and actively introduce high-quality talents to enhance the technical level, and establish a corresponding talent incentive mechanism to improve the business level of monitoring personnel and monitoring capabilities.

\subsection{Strengthen government management and supervision}

The government should specify a dedicated agency for environmental management of water sources, clarify responsibilities, strengthen departmental cooperation and information sharing, and implement comprehensive decision-making in the water source construction and protection sector. At the same time, according to the actual situation of each place, innovative management system for the use and storage of drinking water. The government should encourage the establishment of a market-oriented mode of operation, the establishment of private drinking water companies, encourage private enterprises and private capital to enter, to marketoriented mode of construction, enterprise mode of management. Clarify the ownership of the company, decentralize the right to build, relax the right to operate, so that private drinking water companies can operate independently. At the same time, the government to implement the overall management and node supervision strategy, for state-run drinking water companies and private drinking water companies using the same standard management, and regular spot checks on drinking water treatment links to achieve water quality supervision, to ensure the quality of drinking water for residents.

\section{Acknowledgement}

This work was supported by Guizhou Provincial Science and Technology Projects (qiankehezhicheng [2018]2775)

\section{References}

1. X. Zhao, S. He and L. Yang. Adsorption mechanisms of heavy metal ions from drinking water by weakly basic anion exchange resins. Tsinghua Science and Technology, 7, 5, 532-538, (2002)

2. N. Mandal, S. Mitra and D. Bandyopadhyay. PaperSensors for Point-of-Care Monitoring of Drinking Water Quality. IEEE Sensors Journal, 19, 18, 79367941 (2019)

3. H. Nguyen, I. Misbah and W. Shih. Smartphone Nano-Colorimetry for On-Demand Multiplex Lead and Mercury Detection and Quantitation in Drinking Water. IEEE Sensors Journal, 20, 12, 6685-6691, 15 (2020).

4. T. P. Lambrou, C. C. Anastasiou, C. G. Panayiotou and M. M. Polycarpou. A Low-Cost Sensor Network for Real-Time Monitoring and Contamination Detection in Drinking Water Distribution Systems. IEEE Sensors Journal, 14 , 2765-2772 (2014)

5. D. Zheng and L. Sun Fluorine contents in crops and water and its health risks assessment in Liaohe River Basin, China. 2011 International Symposium on Water Resource and Environmental Protection, Xi'an, 2314-2316 (2011) 